\title{
Patient perceptions of their glycemic control and its influence on type 2 diabetes outcomes: an international survey of online communities
}

This article was published in the following Dove Medical Press journal: Patient Preference and Adherence

\author{
Kristina Simacek' \\ Christopher Curran' \\ Peter Fenici ${ }^{2}$ \\ Ricardo Garcia-Sanchez ${ }^{3}$ \\ 'PatientsLikeMe, Inc., Cambridge, MA, \\ USA $;{ }^{2}$ AstraZeneca, Cambridge, UK; \\ ${ }^{3}$ AstraZeneca, Gaithersburg, MD, USA
}

\begin{abstract}
Purpose: This study aimed to assess awareness of glycated hemoglobin (A1C) testing and targets, perceived level of glycemic control and risk of complications, attitudes toward medications and self-management, and regimen-related distress in an international sample of patients with type 2 diabetes (T2D).
\end{abstract}

Methods: The descriptive study used a single time-point survey of adults in online health communities in the USA, Canada, the UK, Germany, Spain, and Mexico, who self-reported T2D diagnosed by a physician.

Results: In total, 661 patients participated. Awareness of their A1C value at last test varied considerably between countries (42\%-89\%), as did awareness of having an A1C target (26\%$70 \%$ ). Self-reported A1C values were similar across US, Canadian, and European respondents (mean, 6.8\%-7.3\%). Approximately two-thirds of respondents from these countries $(66 \%-71 \%)$ reported that their T2D was very or fairly well controlled, and few $(5 \%-15 \%)$ expected to experience serious complications within 1 year. However, many respondents expected to experience microvascular (rather than macrovascular) complications in this time frame (eg, nerve pain, 5\%-47\%). Self-reported adherence to oral medication was generally high, with most respondents $(86 \%-98 \%)$ taking their pills or tablets as directed by their healthcare provider, although for insulin injections adherence was lower in the USA (71\%) and Mexico (78\%) than in the other countries $(86 \%-95 \%)$. The majority of respondents across countries $(71 \%-79 \%)$ reported that taking injectable medications was not at all or a little burdensome. Respondents across countries appeared to be reasonably confident that they could adequately manage their blood sugar levels; despite this, a sizeable minority $(21 \%-35 \%)$ had clinically significant levels of regimen-related distress.

Conclusion: Limited patient awareness of their A1C value and the potential complications of poorly controlled T2D, particularly regarding cardiovascular complications, may be a widespread problem. Furthermore, greater patient support may be needed to improve self-management of $\mathrm{T} 2 \mathrm{D}$ and to reduce regimen-related distress.

Keywords: diabetes mellitus, type 2, diabetes complications, glycated hemoglobin, selfmanagement, surveys

\section{Introduction}

Adequate glycemic control is crucial to reducing the risk of complications from type 2 diabetes (T2D), which can include myocardial infarction, stroke, peripheral artery disease, lower limb amputation, vision loss, heart failure, nephropathy, retinopathy, and neuropathy. ${ }^{1}$ Evidence-based guidelines for management of T2D recommend a combination of lifestyle changes and medication (insulin and oral hypoglycemic agents) 
to control blood glucose, as well as medication to control the cardiovascular disease risk and regular screening for early detection of complications. ${ }^{1,2}$ These guidelines typically stipulate that patients with T2D should have an individualized glycated hemoglobin (A1C) target, often aiming for as low as $7.0 \%$ or $6.5 \%$, depending on additional patient-specific factors such as age, duration of diabetes, comorbidities, and risk of hypoglycemia. ${ }^{2-5}$ However, despite the availability of these guidelines, patients' glycemic control appears to remain suboptimal to various degrees worldwide, ${ }^{6,7}$ including in both high-income ${ }^{8,9}$ and low to medium-income countries. ${ }^{10}$ In the MOSAIc study, for example, a multinational, longitudinal, observational study of adults with T2D using insulin, the mean participant A1C value across 18 countries at baseline was $8.2 \%$, despite a mean target $\mathrm{A} 1 \mathrm{C}$ of $6.9 \% .^{7}$ This study also showed that there is considerable variation among countries in terms of patients' demographic characteristics, medical histories, drug treatment regimens, and self-reported knowledge of, and distress about, diabetes. ${ }^{7}$

Patient self-management is a critical aspect of T2D care. Patients' knowledge and perceptions of their glycemic control and T2D medication can impact treatment adherence and diabetes outcomes. Several studies have shown that limited numbers of patients are aware of their current and target A1C levels. ${ }^{11-13}$ In addition, patients' adherence to their T2D medication can be limited by critical beliefs about their medications (such as perceived treatment inefficacy), and the perceived burden regarding obtaining and taking their medication (including treatment complexity, out-of-pocket costs, and hypoglycemia). ${ }^{14,15}$ Patients with elevated A1C levels who display poor self-management behavior are less likely to receive treatment intensification, ${ }^{16,17}$ thereby prolonging or exacerbating their inadequate glycemic control. However, it is not clear what patients perceive to be the consequences of poor glycemic control, or how this may vary between countries.

Online health communities aim to bring patients together to share their experiences and offer support for living with conditions such as diabetes. These communities offer an opportunity to exchange information outside of the clinic environment. The aims of this survey-based international study of patients with T2D in online health communities were to assess the level of patient awareness of A1C testing and targets, to uncover patient attitudes toward, and preferences for, T2D pharmacological treatments, and to determine patient-perceived consequences of poor glycemic control. Patients from Canada, Germany, Mexico, Spain, the UK, and the USA were surveyed. The prevalence of diabetes among adults in these countries ranges from $5.9 \%$ in the UK to $14.0 \%$ in Mexico (Table S1) ${ }^{18}$ The general target A1C value for most adults with T2D stipulated by each country's national T2D management guidelines is $7.0 \%$ or below, with the exception of the German guidelines that recommend a target range of $6.5 \%-7.5 \%$ (Table $\mathrm{S} 1$ ), and all advise that the target should be tailored to the individual patient. ${ }^{3,19-23}$

\section{Methods}

\section{Study population and conduct}

Patients aged 18 years or older who resided in Canada, Germany, Mexico, Spain, the UK, or the USA and who self-reported that they had been diagnosed with T2D by a physician were eligible to participate in the study. Patients also had to be able to read and understand the language in which the survey was presented, which was the official language of the country (ie, English, German, or Spanish). Those patients who were diagnosed with T2D within the previous 6 months were excluded, because they may not have had sufficient experience of their diabetes to answer the questions in an informed manner.

Approval to field the survey in the USA and Canada was granted by the Western Institutional Review Board (Puyallup, WA, USA; Vancouver, BC, Canada) and was not required in the other countries. The appropriate regulatory bodies in the UK (Health Research Authority) and Spain (Agencia Española de Medicamentos y Productos Sanitarios), and local colleagues in Germany and Mexico, confirmed that approval was not required to field the survey in these countries. Participants gave their informed consent by completion of an online form before taking the survey.

\section{Data source}

Data for this descriptive study were obtained by surveying patients who were members of online health communities hosted by PatientsLikeMe (for patients resident in the USA and Canada), Carenity (for patients resident in Germany, Spain, and the UK), or HealthUnlocked (for patients resident in Mexico). Eligible members of the PatientsLikeMe platform were invited to participate through a private message sent to their account, directing them to the study on the PatientsLikeMe website. Users who did not complete the survey received up to three reminders. Eligible members of T2D communities hosted by Carenity and HealthUnlocked were sent pop-up invitations, weekly for Carenity members and once only for HealthUnlocked members, that directed them to internal landing pages for the study within the Carenity or HealthUnlocked platforms. Invitations were sent in members' native languages. The survey was fielded for 
2 weeks, or until a sample of 100 respondents per country was achieved.

\section{Survey instrument}

The single time-point survey was designed to assess patient perceptions and attitudes about A1C and its impact on health outcomes (Appendix S1). The survey also included a series of questions on goal-setting, management of diabetes, treatments, and adherence, as well as demographic and health history information (Table S2).

Survey items were derived from the results of targeted literature reviews $s^{6,7,11,14,24-26}$ and the relevant experience of the authors. Perceived diabetes control was assessed as in a previous cross-national study: ${ }^{25}$ participants were asked whether they believed that their last $\mathrm{A} 1 \mathrm{C}$ test result meant that they were doing well or poorly on a four-point Likert scale (very well, fairly well, fairly poorly, very poorly), or they could select "I don't know." In addition, participants were asked to rate the distress associated with taking their diabetes medication, using the Regimen-Related Distress domain of the Diabetes Distress Scale (DDS). ${ }^{27}$

The survey was prepared in English and translated into the official language of each country from which participants were drawn. A series of iterative survey language checks among investigators, and electronic pretesting for design elements, question ordering, and survey flow, were conducted before the survey launch.

\section{Statistical analyses}

All nonresponse options were treated as missing values and coded as null. Multisite data were aggregated and cleaned in RStudio version 1.0.143, with $\mathrm{R}$ version 3.0.0, utilizing the packages "dplyr" and "lubridate." Analyses were conducted using SAS Enterprise Guide version 7.13 (SAS Institute Inc., Cary, NC, USA). Descriptive statistics were generated for variables of interest.

\section{Results}

\section{Participant demographics and characteristics}

The response rate for the survey ranged from below $1 \%$ in Mexico to 39\% in Canada (Table S3). In total, 661 respondents were included in the study (Table 1). There were slight differences between countries in the age of study participants, with German participants being older than American, Canadian, and Mexican participants. A slightly higher proportion of women than men participated in the study overall (53\% vs $47 \%$ ); the difference in proportions was most pronounced in the USA. The spread of responses for time since T2D diagnosis was similar across all countries, with most participants being diagnosed between 1 and 15 years previously. Respondents across countries typically saw a primary care physician/general practitioner for their T2D care, with other commonly seen healthcare providers (HCPs) being diabetologists for German respondents, endocrinologists for Spanish respondents, and nurse practitioners for UK respondents.

\section{Awareness of diabetes tests, $A I C$ test results, and AIC targets}

There was variation between countries in the routine tests that respondents reported their HCPs performed regularly (Table 2). Most respondents across countries were aware that their A1C level had been assessed in the past. Respondents from Mexico and Spain reported the lowest rates of $\mathrm{A} 1 \mathrm{C}$ testing on a regular basis, with $18 \%$ of Mexican respondents believing that their HCP had never tested their A1C level. By contrast, almost all US respondents were aware that their A1C level had been tested, and 97\% reported regular testing.

Of respondents who reported having their A1C tested, the majority across countries reported that their most recent test occurred within the last 3 months (Table 2). Respondents' ability to recall their $\mathrm{A} 1 \mathrm{C}$ value at last test varied considerably between countries, with more respondents from the USA, Germany, and Spain providing a response than those from Canada and the UK. The mean (SD) self-reported A1C value at last test was largely consistent across countries (6.8 [1.3]-7.3 [1.6]\%), with over half of respondents (57\%) reporting an $\mathrm{A} 1 \mathrm{C}$ level of at least $7.0 \%$. Two-thirds of respondents $(68 \%$ overall) reported that their last $\mathrm{A} 1 \mathrm{C}$ test result indicated that they were doing very or fairly well.

Approximately two-thirds of North American and German respondents reported that they had an A1C target, but this proportion was only $38 \%$ for Spanish respondents and $26 \%$ for UK respondents (Table 2). Of those respondents who reported having an $\mathrm{A} 1 \mathrm{C}$ target, the highest mean value was reported by UK respondents $(6.9[1.0] \%)$ and the lowest was reported by Spanish respondents (6.1 [1.4]\%). The $\mathrm{A} 1 \mathrm{C}$ test result that respondents felt would make them ask their HCP to change their treatment plan ranged from a mean of $7.6(2.1) \%$ for UK respondents to $8.6(1.3) \%$ for Canadian respondents.

\section{Perceptions of diabetes control and complications}

Respondents' perceptions of their level of diabetes control were fairly consistent across countries, with approximately 
Table I Participant self-reported demographics and characteristics

\begin{tabular}{|c|c|c|c|c|c|c|}
\hline & $\begin{array}{l}\text { USA } \\
(n=\mid 48)\end{array}$ & $\begin{array}{l}\text { Canada } \\
(\mathrm{n}=|| 3)\end{array}$ & $\begin{array}{l}\text { Germany } \\
(n=100)\end{array}$ & $\begin{array}{l}\text { Mexico } \\
(n=100)\end{array}$ & $\begin{array}{l}\text { Spain } \\
(n=100)\end{array}$ & $\begin{array}{l}\text { UK } \\
(n=100)\end{array}$ \\
\hline Age (years), mean (SD) & $58(8.9)$ & $58(9.7)$ & $62(8.8)$ & $56(7.8)^{\mathrm{a}}$ & $60(9.2)$ & $60(8.0)$ \\
\hline \multicolumn{7}{|l|}{ Sex, n (\%) } \\
\hline Female & $99(67)$ & $62(55)$ & $45(45)$ & $49(49)$ & $42(42)$ & $55(55)$ \\
\hline Male & $48(32)$ & $51(45)$ & $55(55)$ & $5 I(5 I)$ & $58(58)$ & $45(45)$ \\
\hline Prefer to skip & $I(I)$ & 0 & 0 & 0 & 0 & 0 \\
\hline \multicolumn{7}{|l|}{ Education, n (\%) } \\
\hline High school graduate or less & $23(16)$ & $35(3 I)$ & $75(75)$ & $42(42)$ & $48(48)$ & $4 I(4 I)$ \\
\hline Some college & $55(37)$ & $45(40)$ & $4(4)$ & $12(12)$ & $22(22)$ & $33(33)$ \\
\hline College graduate or greater & $70(47)$ & $33(29)$ & $2 I(2 I)$ & $46(46)$ & $30(30)$ & $26(26)$ \\
\hline \multicolumn{7}{|l|}{ Comorbidities, n (\%) } \\
\hline Overweight/obesity & $114(81)$ & $75(70)$ & $69(69)$ & $5 I(5 I)$ & $64(64)$ & $74(74)$ \\
\hline High blood pressure (hypertension) & $105(75)$ & $69(65)$ & $73(73)$ & $47(47)$ & $57(57)$ & $73(73)$ \\
\hline High cholesterol (hypercholesterolemia) & $94(67)$ & $67(62)$ & $45(45)$ & $42(42)$ & $47(47)$ & $69(69)$ \\
\hline Depression (MDD, dysthymia) & $7 I(5 I)$ & $37(35)$ & $27(27)$ & $12(12)$ & $18(18)$ & $50(50)$ \\
\hline Neuropathy & $61(44)$ & $32(30)$ & $3 I(3 I)$ & $28(28)$ & $13(13)$ & $25(25)$ \\
\hline Peripheral vascular disease & $24(17)$ & $8(7)$ & $2 I(2 I)$ & $12(12)$ & $14(14)$ & $9(9)$ \\
\hline Retinopathy & $19(14)$ & $17(16)$ & $9(9)$ & $13(13)$ & II (II) & $13(13)$ \\
\hline Heart disease & $23(16)$ & $9(8)$ & $18(18)$ & $2(2)$ & $9(9)$ & $7(7)$ \\
\hline Heart attack (myocardial infarction) & $8(6)$ & $12(11)$ & II (II) & $4(4)$ & $7(7)$ & $7(7)$ \\
\hline Chronic kidney disease & $17(12)$ & $2(2)$ & $6(6)$ & $2(2)$ & $6(6)$ & $6(6)$ \\
\hline Stroke & $5(4)$ & $3(3)$ & $5(5)$ & $I(I)$ & $5(5)$ & $I(I)$ \\
\hline \multicolumn{7}{|l|}{ Time since diagnosis, $\mathrm{n}(\%)$} \\
\hline 6 months to $<1$ year & II (7) & $12(1 \mathrm{I})$ & $0(0)$ & $4(4)$ & $5(5)$ & $0(0)$ \\
\hline $\mathrm{I}-5$ years & $37(25)$ & $30(27)$ & $29(29)$ & $27(27)$ & $28(28)$ & $25(25)$ \\
\hline $6-10$ years & $33(22)$ & $33(29)$ & $28(28)$ & $29(29)$ & $30(30)$ & $27(27)$ \\
\hline $11-15$ years & $29(20)$ & $18(16)$ & $22(22)$ & $23(23)$ & $23(23)$ & $29(29)$ \\
\hline $16-20$ years & $23(16)$ & $13(12)$ & $8(8)$ & II (II) & $7(7)$ & $12(12)$ \\
\hline$>20$ years & $15(10)$ & $7(6)$ & $13(13)$ & $6(6)$ & $7(7)$ & 7 (7) \\
\hline \multicolumn{7}{|l|}{ Symptoms, n (\%) } \\
\hline Hypoglycemia & $51(34)$ & $39(35)$ & $15(15)$ & $19(19)$ & $22(22)$ & $24(24)$ \\
\hline Fatigue & $112(76)$ & $86(76)$ & $56(56)$ & $53(53)$ & 49 (49) & $73(73)$ \\
\hline Insomnia or difficulty sleeping & $90(61)$ & $72(64)$ & $47(47)$ & $39(39)$ & $4 I(4 I)$ & $59(59)$ \\
\hline Dizziness or fainting & $50(34)$ & $42(37)$ & $18(18)$ & $12(12)$ & $15(15)$ & $34(34)$ \\
\hline Nerve pain & $68(46)$ & $47(42)$ & $33(33)$ & $17(17)$ & $10(10)$ & $33(33)$ \\
\hline Problems concentrating & $71(48)$ & $52(46)$ & $26(26)$ & $19(19)$ & $18(18)$ & $45(45)$ \\
\hline Joint stiffness & $85(57)$ & $62(55)$ & $32(32)$ & $17(17)$ & $23(23)$ & $55(55)$ \\
\hline Frequent urination & $72(49)$ & $63(56)$ & $52(52)$ & $34(34)$ & $39(39)$ & $48(48)$ \\
\hline \multicolumn{7}{|l|}{ Providers seen for T2D care, $n(\%)^{d}$} \\
\hline PCP or GP & $125(84)$ & $93(82)$ & $67(67)$ & $65(65)$ & $65(65)$ & $60(60)$ \\
\hline Endocrinologist & $36(24)$ & $17(15)$ & $2(2)$ & $16(16)$ & $4 I(4 I)$ & $6(6)$ \\
\hline Diabetologist & $2(1)$ & $10(9)$ & $55(55)$ & $24(24)$ & $7(7)$ & $15(15)$ \\
\hline Cardiologist & $9(6)$ & $4(4)$ & II (II) & $7(7)$ & $8(8)$ & $I(I)$ \\
\hline Pharmacist & $12(8)$ & $20(18)$ & $3(3)$ & $0(0)$ & $4(4)$ & $4(4)$ \\
\hline Nurse practitioner & $14(9)$ & $12(11)$ & $0(0)$ & $I(I)$ & $24(24)$ & $65(65)$ \\
\hline Certified diabetes educator & $15(10)$ & $16(14)$ & $9(9)$ & $6(6)$ & $5(5)$ & $3(3)$ \\
\hline Podiatrist & $17(11)$ & $10(9)$ & $20(20)$ & $4(4)$ & $9(9)$ & $18(18)$ \\
\hline Dietitian & $5(3)$ & $20(18)$ & I (I) & $16(16)$ & $3(3)$ & $10(10)$ \\
\hline
\end{tabular}

Notes: ${ }^{a}$ An additional three participants from Mexico were reported as being aged $<\mathrm{I}$ year and were removed from the entire data set. ${ }^{\mathrm{b}} \mathrm{Comorbidities} \mathrm{were} \mathrm{chosen} \mathrm{from}$ a list of options. Study participants may have had other comorbidities not reported here. 'Symptoms were selected from a list of common T2D symptoms. ${ }^{\mathrm{A}} \mathrm{A}$ list of types of providers who may be involved in T2D care was presented. Response options were not mutually exclusive. Only providers seen by $>10 \%$ of participants in any country are shown.

Abbreviations: GP, general practitioner; MDD, major depressive disorder; PCP, primary care physician; T2D, type 2 diabetes.

two-thirds $(60 \%)$ of respondents, other than those in Mexico (43\%), reporting that their diabetes was very well or fairly well controlled (Figure 1A). Spanish respondents were the most likely to indicate that, if they stayed at their current level of diabetes control, they did not expect any future diabetes-related complications (Figure 1B). Almost half of US and Canadian respondents expected complications within 5 years, compared with about one-quarter of respondents from the other countries. 
Table 2 Participant-reported diabetes tests, AIC test results, and AIC targets

\begin{tabular}{|c|c|c|c|c|c|c|}
\hline & $\begin{array}{l}\text { USA } \\
(n=\mid 48)\end{array}$ & $\begin{array}{l}\text { Canada } \\
(n=|| 3)\end{array}$ & $\begin{array}{l}\text { Germany } \\
(n=\mid 00)\end{array}$ & $\begin{array}{l}\text { Mexico } \\
(n=100)\end{array}$ & $\begin{array}{l}\text { Spain } \\
(n=100)\end{array}$ & $\begin{array}{l}\text { UK } \\
(n=100)\end{array}$ \\
\hline \multicolumn{7}{|l|}{$\begin{array}{l}\text { Which tests does your doctor normally do to check on } \\
\text { your diabetes? n (\%) }\end{array}$} \\
\hline AIC & I 44 (97) & 87 (77) & $85(85)$ & $23(23)$ & $44(44)$ & $82(82)$ \\
\hline Self-monitoring with a blood sugar meter at home & $117(79)$ & $89(79)$ & $76(76)$ & $57(57)$ & $69(69)$ & $66(66)$ \\
\hline Fasting plasma glucose & $73(49)$ & $73(65)$ & $55(55)$ & $70(70)$ & $67(67)$ & $33(33)$ \\
\hline Checking for sugar in urine & $\begin{array}{l}34(23) \\
(n=148)\end{array}$ & $\begin{array}{l}30(27) \\
(n=I 13)\end{array}$ & $\begin{array}{l}31(3 \mid) \\
(n=100)\end{array}$ & $\begin{array}{l}19(19) \\
(n=100)\end{array}$ & $\begin{array}{l}12(12) \\
(n=100)\end{array}$ & $\begin{array}{l}48(48) \\
(n=100)\end{array}$ \\
\hline \multicolumn{7}{|l|}{ Has your healthcare provider ever tested your AIC? n (\%) } \\
\hline Yes & 147 (99) & $96(85)$ & $88(88)$ & $72(72)$ & $75(75)$ & $82(82)$ \\
\hline No & $0(0)$ & $2(2)$ & $\mathrm{I}(\mathrm{I})$ & $18(18)$ & $4(4)$ & $3(3)$ \\
\hline \multirow[t]{2}{*}{ I don't know } & $\mathrm{I}(\mathrm{I})$ & $15(13)$ & $11(11)$ & $10(10)$ & $21(21)$ & $15(15)$ \\
\hline & $(n=148)$ & $(n=\mid 13)$ & $(n=100)$ & $(n=100)$ & $(n=100)$ & $(n=100)$ \\
\hline \multicolumn{7}{|l|}{ When did you last have an AIC test? n (\%) } \\
\hline Within the last 3 months & $105(71)$ & $62(65)$ & $77(88)$ & $43(60)$ & $38(5 \mathrm{I})$ & $40(49)$ \\
\hline Between 3 and 6 months & $26(18)$ & $21(22)$ & $8(9)$ & $11(15)$ & $16(21)$ & $14(17)$ \\
\hline Between 6 months and I year & $14(10)$ & 7 (7) & $2(2)$ & $6(8)$ & $16(21)$ & $21(26)$ \\
\hline$>1$ year & $I(I)$ & $5(5)$ & $I(I)$ & $12(17)$ & $5(7)$ & $6(7)$ \\
\hline \multirow[t]{2}{*}{ I don't know } & $I(1)$ & $1(1)$ & $0(0)$ & $0(0)$ & $0(0)$ & I (I) \\
\hline & $(n=147)$ & $(n=96)$ & $(n=88)$ & $(n=72)$ & $(n=75)$ & $(n=82)$ \\
\hline \multicolumn{7}{|l|}{ What was your last measured $\%$ AIC value? } \\
\hline Mean (SD) & $7.3(1.6)$ & $7.2(1.2)$ & $7.3(1.4)$ & - & $6.8(1.3)$ & $7.2(1.5)$ \\
\hline$<6.0, \mathrm{n}(\%)$ & $21(16)$ & $5(9)$ & $4(5)$ & - & $2(4)$ & $3(7)$ \\
\hline $6.0-6.9, \mathrm{n}(\%)$ & $46(35)$ & $18(33)$ & $18(22)$ & - & $26(48)$ & $14(33)$ \\
\hline $7.0-7.9, \mathrm{n}(\%)$ & $33(25)$ & $18(33)$ & $32(40)$ & - & $18(33)$ & II (26) \\
\hline \multirow[t]{2}{*}{$\geq 8.0, \mathrm{n}(\%)$} & $32(24)$ & $14(25)$ & $27(33)$ & - & $8(15)$ & $14(33)$ \\
\hline & $(n=132)$ & $(n=55)$ & $(n=8 I)$ & - & $(n=54)$ & $(n=42)$ \\
\hline \multicolumn{7}{|l|}{ What do you think your last AIC test result means? n (\%) } \\
\hline Doing very well & $36(25)$ & $18(19)$ & $7(8)$ & $13(23)$ & $10(15)$ & $13(38)$ \\
\hline Doing fairly well & $62(43)$ & $45(47)$ & $57(67)$ & $15(27)$ & $36(55)$ & $16(47)$ \\
\hline Doing fairly poorly & $36(25)$ & $23(24)$ & $14(16)$ & $18(32)$ & $8(12)$ & $0(0)$ \\
\hline Doing very poorly & $12(8)$ & $4(4)$ & $5(6)$ & $7(13)$ & $5(8)$ & $3(9)$ \\
\hline \multirow[t]{2}{*}{ I don't know } & $0(0)$ & $5(5)$ & $2(2)$ & $3(5)$ & $6(9)$ & $2(6)$ \\
\hline & $(n=146)$ & $(n=95)$ & $(n=85)$ & $(n=56)$ & $(n=65)$ & $(n=34)$ \\
\hline \multicolumn{7}{|l|}{$\begin{array}{l}\text { Do you and your healthcare provider have a specific AIC } \\
\text { target or goal? n (\%) }\end{array}$} \\
\hline Yes & $102(70)$ & $60(63)$ & $59(59)$ & $36(64)$ & $38(38)$ & $26(26)$ \\
\hline No & $4 \mid(28)$ & $27(28)$ & $36(36)$ & $7(13)$ & $45(45)$ & $69(69)$ \\
\hline \multirow[t]{2}{*}{ I don't know } & $3(2)$ & $8(8)$ & $5(5)$ & $13(23)$ & $17(17)$ & $5(5)$ \\
\hline & $(n=\mid 46)$ & $(\mathrm{n}=95)$ & $(n=100)$ & $(\mathrm{n}=56)$ & $(n=100)$ & $(n=100)$ \\
\hline \multirow[t]{2}{*}{ What is your \% AIC goal or target? Mean (SD) } & $6.4(0.7)$ & $6.4(0.7)$ & $6.4(0.7)$ & - & $6.1(1.4)$ & $6.9(1.0)$ \\
\hline & $(n=95)$ & $(n=44)$ & $(n=54)$ & - & $(n=54)$ & $(n=20)$ \\
\hline How high would your $\%$ AIC test result have to be for & $7.9(1.6)$ & $8.6(1.3)$ & $7.9(1.1)$ & - & $8.0(1.3)$ & $7.6(2.1)$ \\
\hline you to ask your doctor to do something about it, such & $(n=110)$ & $(n=46)$ & $(n=64)$ & - & $(n=43)$ & $(n=33)$ \\
\hline as make a change to your treatment plan? Mean (SD) ${ }^{\mathrm{a}}$ & & & & & & \\
\hline
\end{tabular}

Notes: a Data for Mexico have not been included owing to suspected confusion between AIC and glucose levels in participant responses. Additionally, data that did not fall between values of 4 and 14 were excluded, with the exception of values of $0.40-0.99$ and $0.10-0.14$; these were assumed to be in the decimal form and were multiplied by 10 or 100 , respectively, and included.

Abbreviation: AIC, glycated hemoglobin.

North American respondents also anticipated a higher number of different complications, both within the next year and after 5 years, than European respondents, assuming that their diabetes remained at the same level of control (Figure 2A and B). Nerve pain, eye problems, sexual dysfunction, skin problems, and kidney problems were the most common complications that respondents reported they were likely to experience.

\section{Diabetes medications and self- management}

Overall, approximately two-thirds of respondents reported that they never missed medical appointments regarding their diabetes, although in Mexico this figure dropped to about half (Figure 3A). Participants across countries reported that they were frequently told by their doctor to take oral 

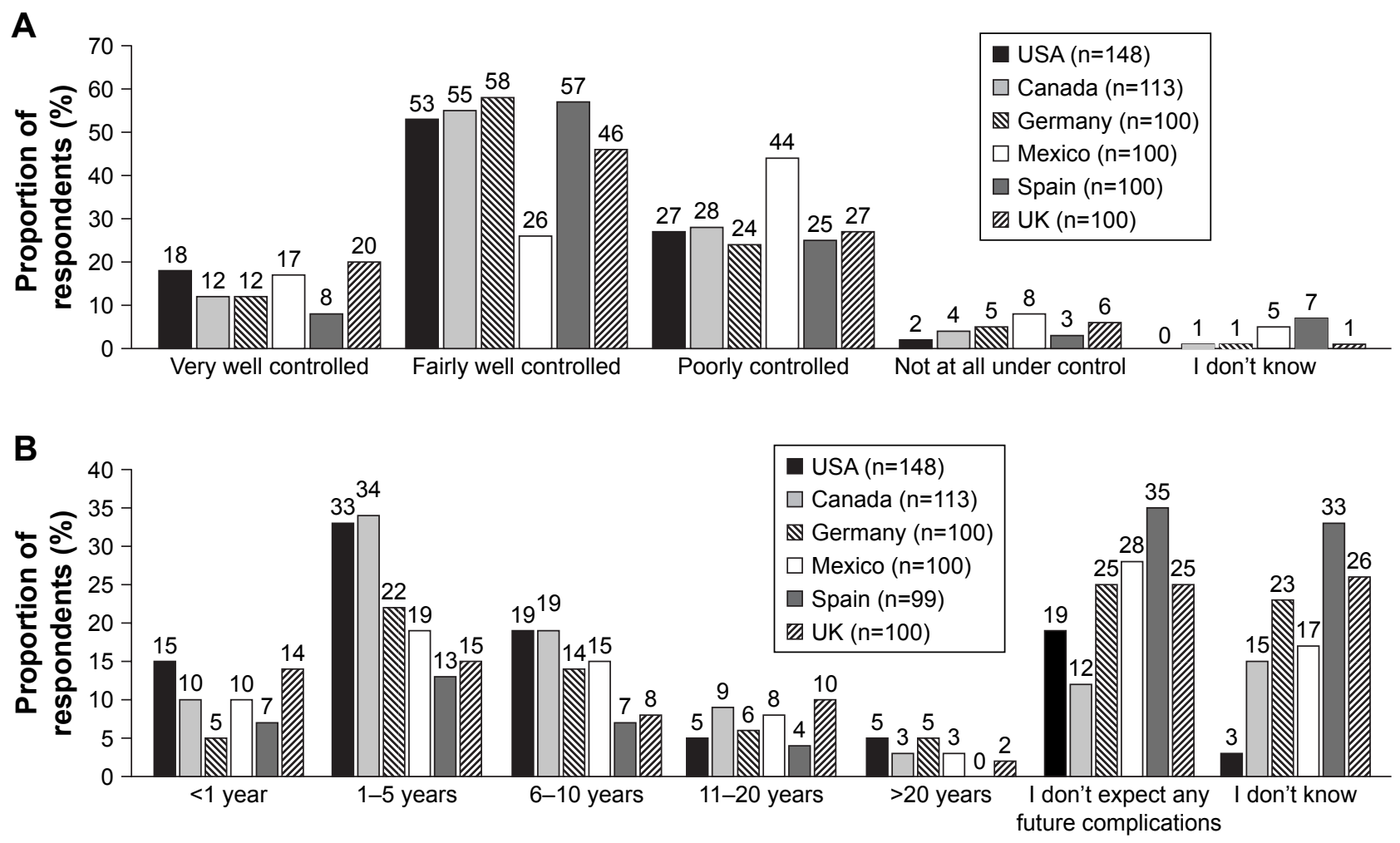

Figure I Participant perceptions of diabetes control and complications (part I).

Notes: Responses to survey questions. (A) To what extent do you believe your diabetes is under control? (B) If you were to stay at your current level of diabetes control, for how long do you think you could avoid any serious complications due to your diabetes?

medications, to increase their levels of exercise, and to change their diet in order to improve their diabetes control (Figure 3B). Self-reported adherence to oral medication and insulin treatment was generally high, although adherence to insulin treatment appeared to be lower in the USA and Mexico than in the other countries (Figure 3C and D). The majority of respondents across countries reported that taking injectable medications was not at all burdensome or was a little burdensome (Figure 4A). When asked how important medications for T2D are in helping them achieve their diabetes goals, the vast majority (89\%) of respondents across countries rated them as very important or important (Figure 4B); however, 27\% of UK respondents said they were a very unimportant factor.

\section{Regimen-related diabetes distress and attitudes toward diabetes self- management}

Overall, approximately one-quarter to one-third of respondents' scores met or exceeded the clinical threshold for the Regimen-Related Distress domain of the DDS, with the highest proportion above the threshold being Canadian respondents and the lowest being German respondents (Table 3).
The majority of respondents were confident that they could avoid serious problems due to low blood sugar when alone, and did not feel that worrying about the possibility of a low blood sugar episode interfered with their ability to do the things they wanted to do (Figure 5A and B). Responses across countries were similar regarding managing blood sugar to avoid hypoglycemic episodes, with approximately one-third of patients keeping their blood sugar levels higher than they should (Figure 5C).

\section{Discussion}

Individualized A1C targets, self-monitoring of blood glucose, and adherence to treatment are key pillars of T2D management guidelines. This survey-based study of patients with T2D in online health communities revealed several insights into patients' awareness of A1C testing and targets, their perceptions of their glycemic control, and their attitudes toward diabetes management.

Previous studies indicate that limited numbers of patients are aware of their current and target A1C levels. ${ }^{11-13}$ The participants in our study who were aware of having an A1C target, approximately half of the total number, generally reported targets that were in line with national guidelines, ${ }^{3,19-23}$ 

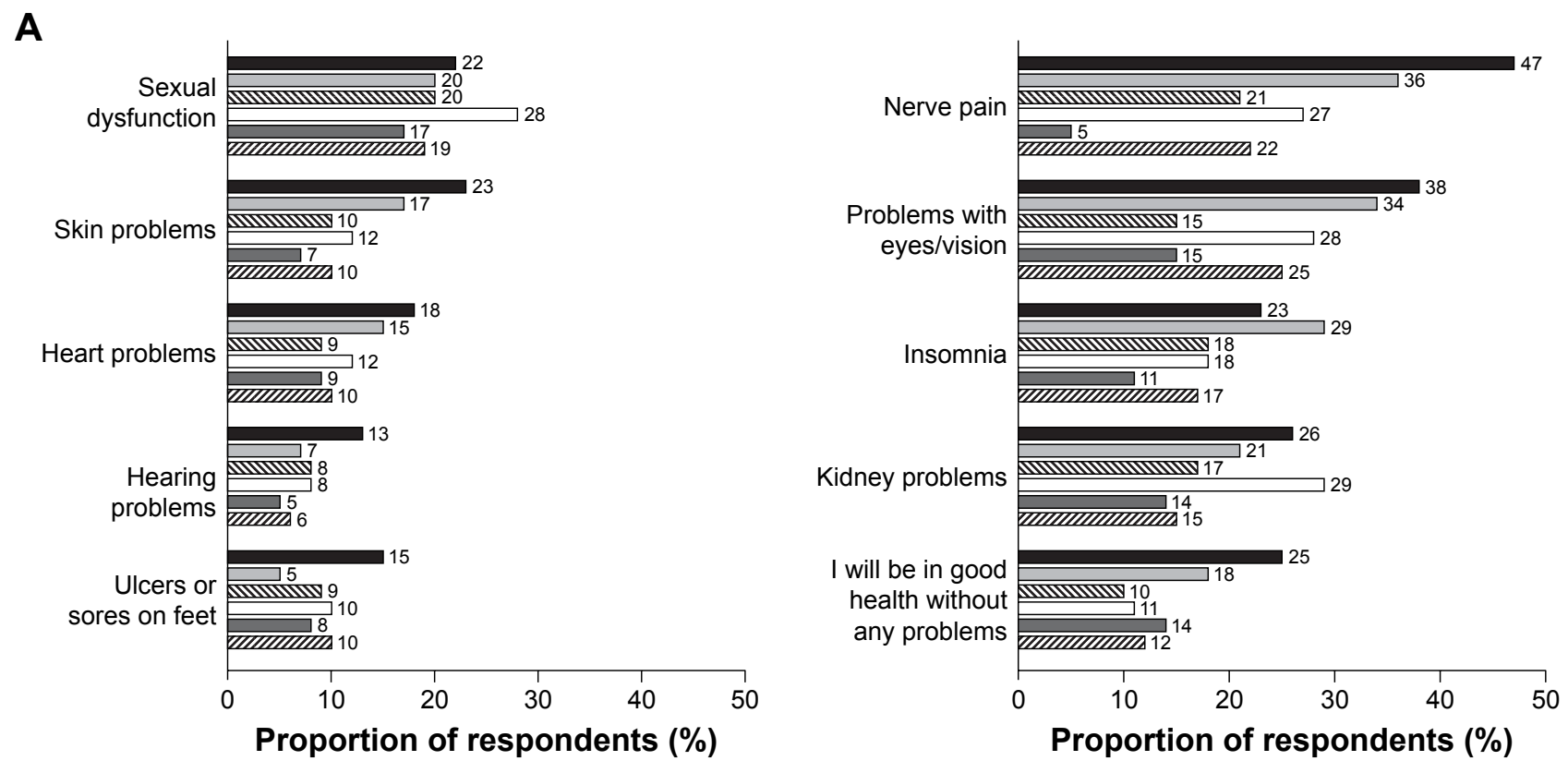

B

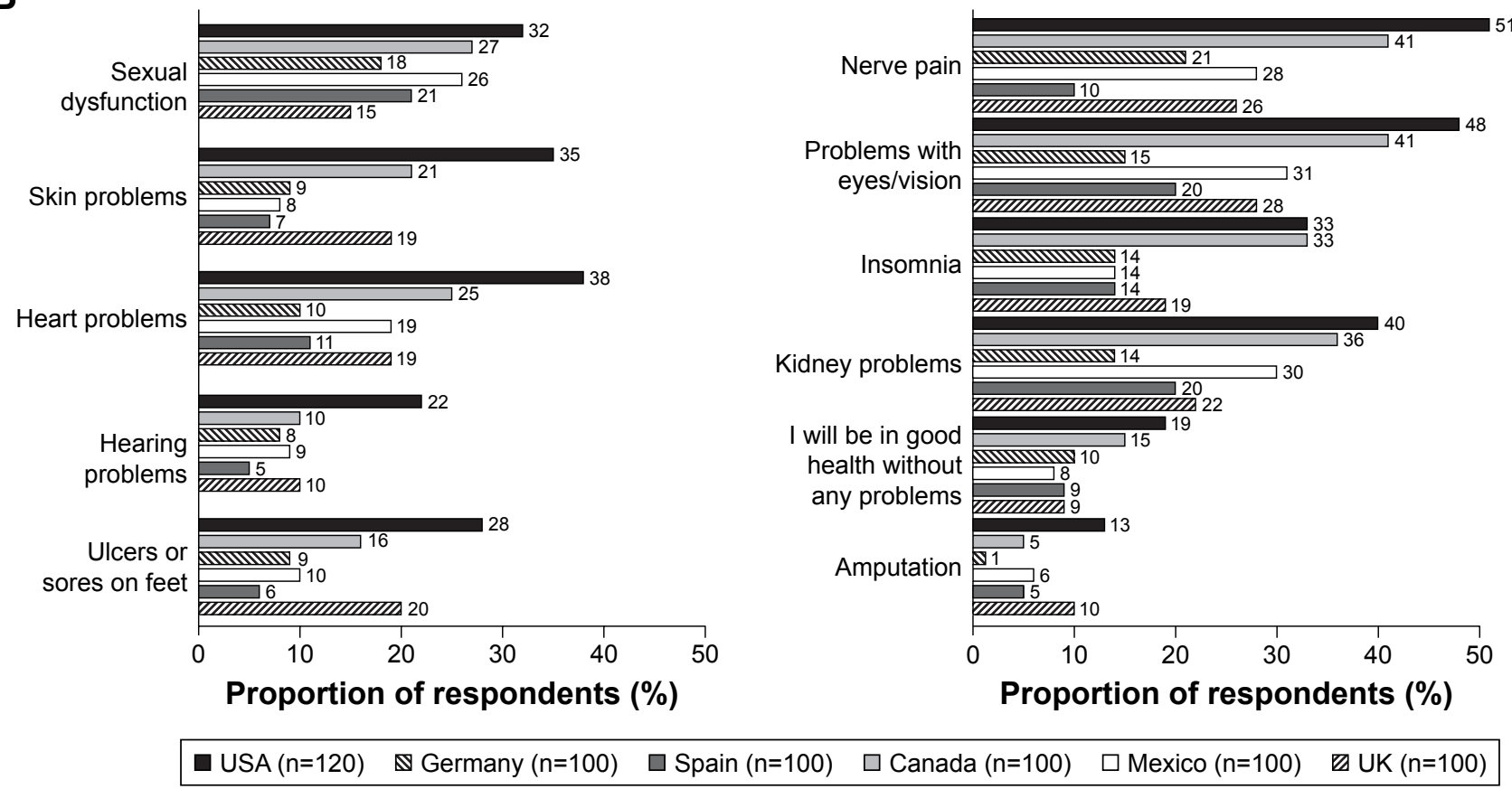

Figure 2 Participant perceptions of diabetes control and complications (part 2).

Notes: Responses to survey questions. (A) What do you think is likely to happen to you in the short term (within I year) if your diabetes stays at the same level of control? (B) What do you think is likely to happen to you in the long term (after 5 years) if your diabetes stays at the same level of control?

with a mean $\mathrm{A} 1 \mathrm{C}$ value of $6.1 \%-6.9 \%$. However, about half of participants who reported an $\mathrm{A} 1 \mathrm{C}$ level at last test gave a value greater than $7.0 \%$, generally considered to be a sign of uncontrolled glycemia, ${ }^{2,3}$ although it should be noted that patient recollections of their last $\mathrm{A} 1 \mathrm{C}$ test result may not be accurate. ${ }^{11,12}$ Participant self-reported target A1C and last $\mathrm{A} 1 \mathrm{C}$ test results were largely consistent between countries, suggesting that any slight differences between the national guidelines do not seem to have a great impact on patients' target and actual $\mathrm{A} 1 \mathrm{C}$ values.

The majority of respondents across countries believed that their last test result indicated that they were doing very or fairly well, and that their diabetes was very or fairly well controlled. However, respondents did not feel that any change to their treatment plan was needed unless their A1C levels hit $7.6 \%-8.6 \%$ on average. This could suggest that patients 


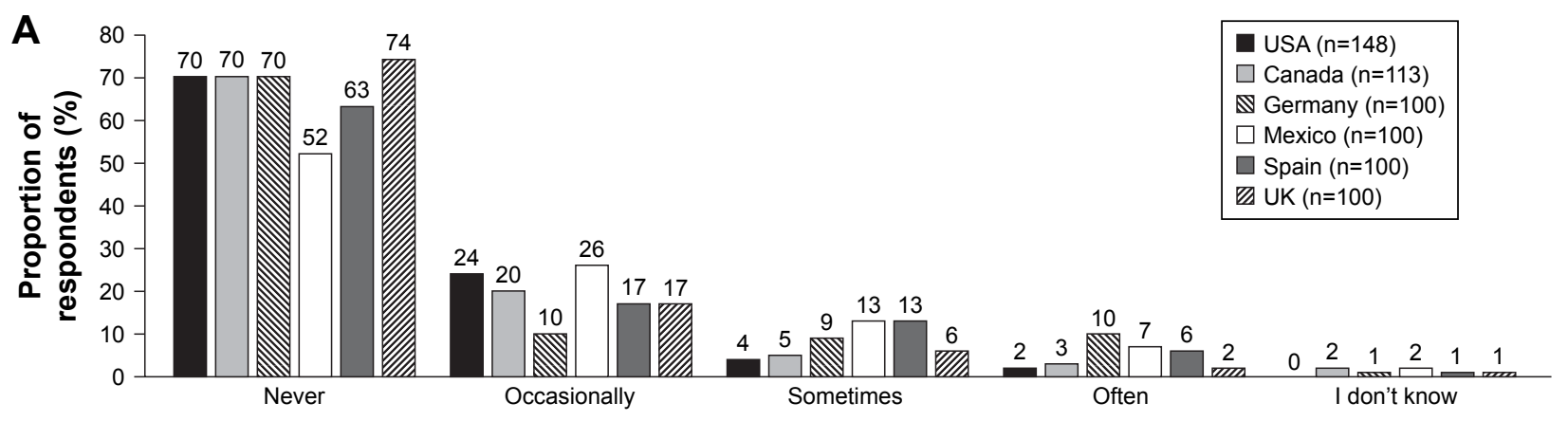

B
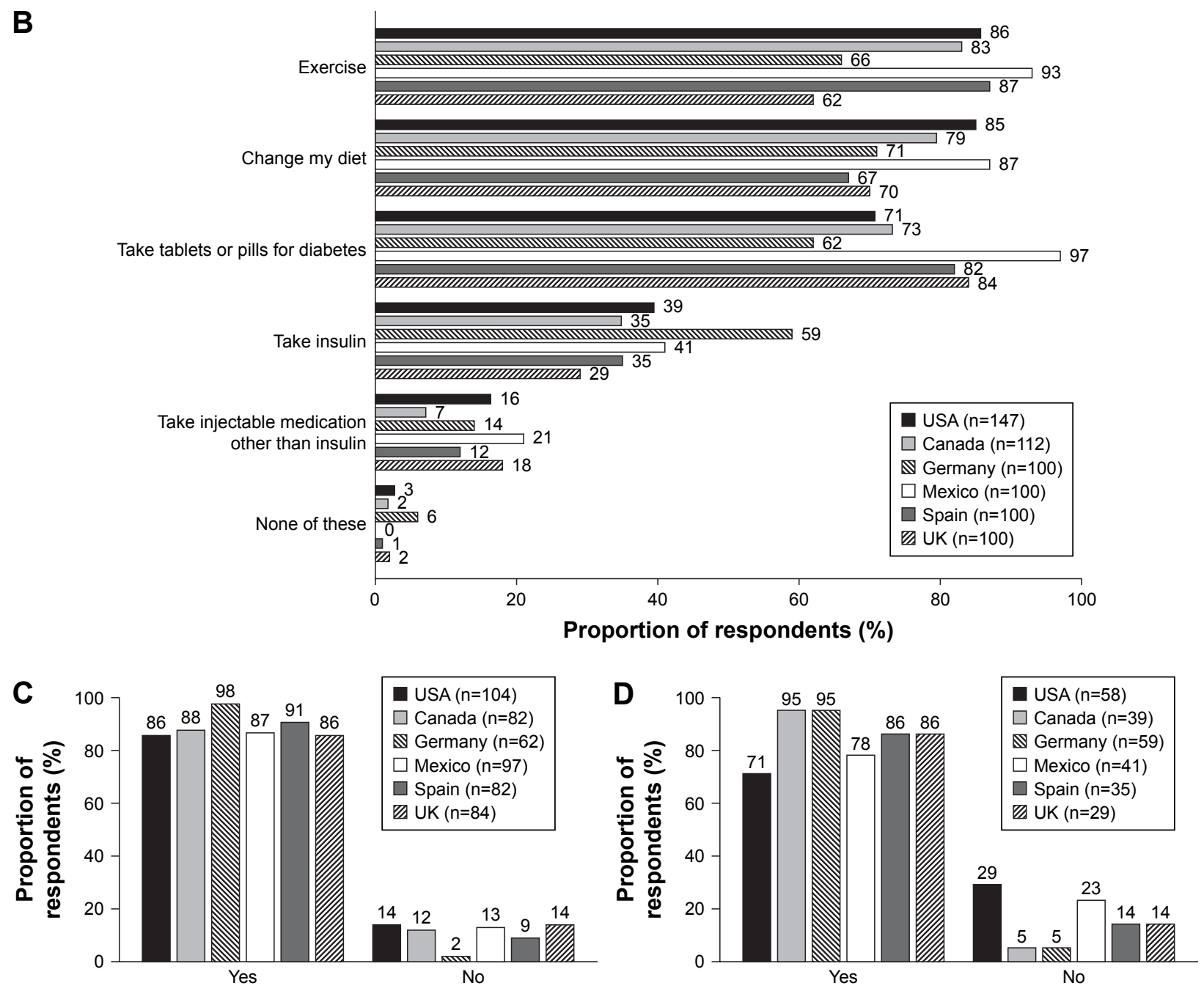

Figure 3 Participant behaviors relating to diabetes management.

Notes: Responses to survey questions. (A) How often do you miss or skip appointments, for any reason, with a healthcare provider to discuss or review your diabetes? (B) What has your doctor told you to do to manage/control your diabetes better? (C) Do you always take your pills or tablets as directed by your healthcare provider? (D) Do you always take your insulin as directed by your healthcare provider?

may overestimate the extent of their diabetes control, considering the A1C target set by their HCP to be an ideal target only and not feeling that action is required unless their A1C is considerably higher than this. Alternatively, HCPs may consider guideline A1C targets to be an ideal, with changes to patient treatment not being required until their $\mathrm{A} 1 \mathrm{C}$ reaches a higher threshold.
Of further concern regarding patient adherence to A1C targets is that only about half of Canadian, Spanish, and UK respondents to our survey could recall their last A1C value, and only about one-third of UK and Spanish respondents were aware that they had an A1C target. In addition, the majority of respondents in Spain and Mexico did not think that their A1C levels were tested regularly by their HCP. 

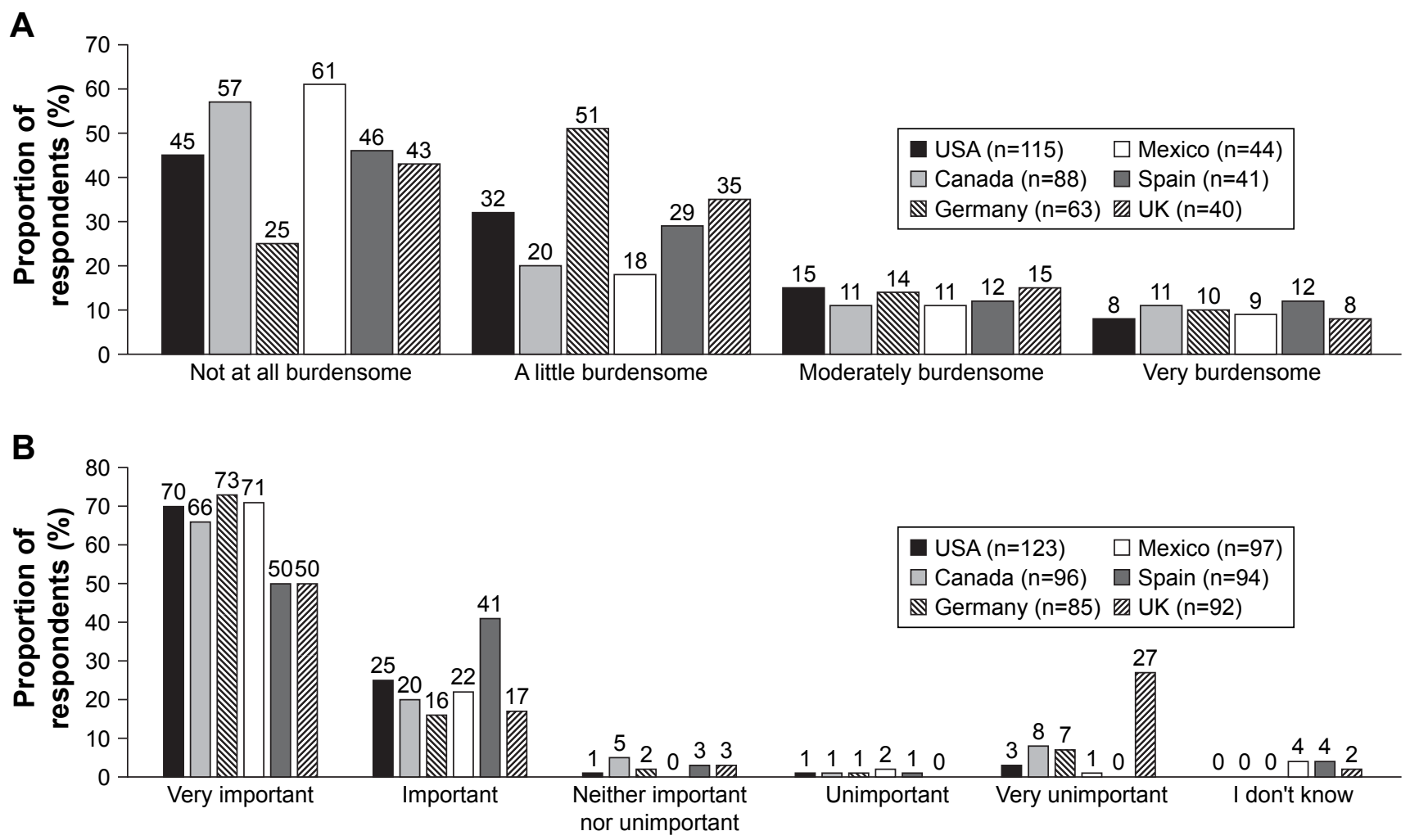

Figure 4 Participant perceptions of diabetes medications.

Notes: Responses to survey questions. (A) How burdensome would you say it is to take your injectable medication for your type 2 diabetes? (B) How important are medicines in helping you achieve your diabetes goals?

By contrast, almost all US respondents reported regular A1C testing, with almost $90 \%$ able to recall their last A1C value and over two-thirds aware that they had an $\mathrm{A} 1 \mathrm{C}$ target. These findings suggest that $\mathrm{AlC}$ tests may be carried out more regularly in some countries than in others, which may be due to economic reasons, or that there may be variation in doctor-patient communication among these countries. In Spain and Mexico, for example, physicians may adopt a more paternalistic model of care than physicians in the USA, Canada, and northern Europe, and may therefore be less likely to communicate in detail about laboratory test results. Indeed, in a survey of patients in European countries, Spain had the lowest patient support for shared decision-making, favoring a doctor-led process $;{ }^{28}$ while in Mexico, doctors are required only to give verbal (rather than written) summaries of medical records to patients. ${ }^{29}$ By contrast, it has been the official policy of the US Department of Health and Human Services since 2014 to give patients direct access to their own test results; ${ }^{30}$ this initiative seems to be reflected in our survey data. Our findings suggest that there is room for improvement in communication of $\mathrm{A} 1 \mathrm{C}$ test results and targets between HCPs and patients in many countries. Patients' awareness of their A1C levels could also be improved by increased remote monitoring feedback via mobile devices and other telehealth technologies, as well as a broader implementation of continuous glucose monitoring with long-term sensors.

Table 3 Participant scores for the Regimen-Related Distress domain of the Diabetes Distress Scale

\begin{tabular}{|c|c|c|c|c|c|c|}
\hline & $\begin{array}{l}\text { USA } \\
(n=\mid 48)\end{array}$ & $\begin{array}{l}\text { Canada } \\
(n=I \mid 3)\end{array}$ & $\begin{array}{l}\text { Germany } \\
(n=100)\end{array}$ & $\begin{array}{l}\text { Mexico } \\
(n=100)\end{array}$ & $\begin{array}{l}\text { Spain } \\
(n=100)\end{array}$ & $\begin{array}{l}\text { UK } \\
(n=100)\end{array}$ \\
\hline $\begin{array}{l}\text { DDS - Regimen-Related } \\
\text { Distress score, mean (SD) }\end{array}$ & $12.4(5.69)$ & I3.I (5.77) & II.I (5.52) & II.9(6.54) & $10.9(6.19)$ & I I.2 (5.88) \\
\hline $\begin{array}{l}\text { Above DDS clinical } \\
\text { threshold }(\geq 3), \%(n)\end{array}$ & 31.8 (47) & 34.5 (39) & $21.0(2 I)$ & $32.0(32)$ & $25.0(25)$ & $32.0(32)$ \\
\hline
\end{tabular}

Notes: The Regimen-Related Distress domain of the DDS comprises five items, such as "how much has this problem bothered you during the last month: feeling that I am often failing with my diabetes regimen." Each item is assessed using a six-point Likert scale, ranging from "Not a problem" to "A very serious problem", scored from one to six. The item scores are summed to give the domain score. This is then divided by five to give a mean score, for which scores of three or higher are considered clinically significant.

Abbreviation: DDS, Diabetes Distress Scale. 

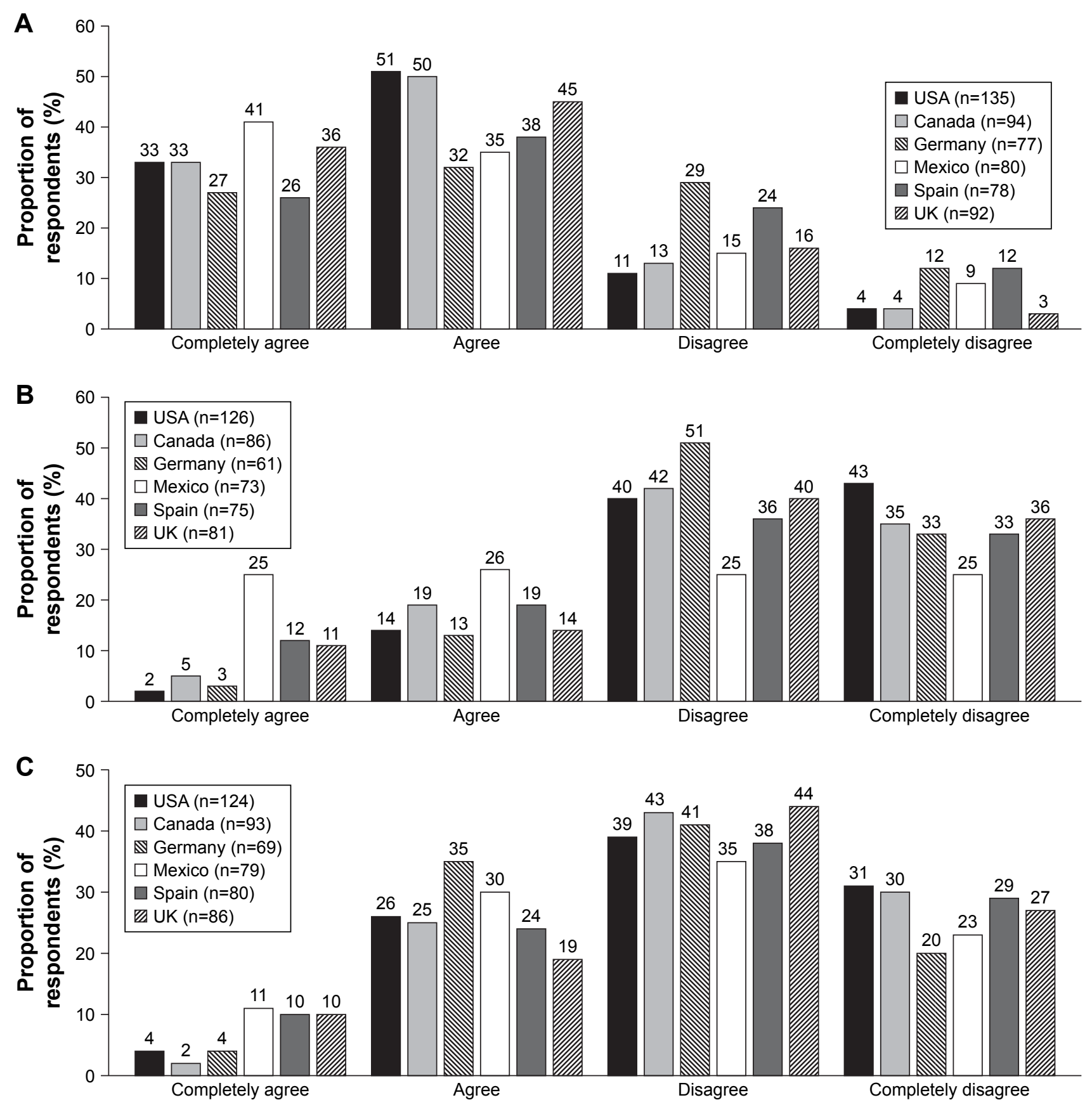

Figure 5 Participant attitudes toward diabetes self-management.

Notes: Responses to survey statements. (A) I am confident that I can avoid serious problems due to low blood sugar when I am alone. (B) I spend so much time worrying about the possibility of a low blood sugar episode that it interferes with my ability to do the things I really want to do. (C) To avoid serious problems with low blood sugar, I tend to keep my blood sugars higher than I probably should.

Although the majority of respondents across countries (other than in Mexico) had similar perceptions of their level of glycemic control, North American respondents expected to experience more diabetes-related complications in the future than their European counterparts, especially those from Spain. This finding may be explained by cultural and regulatory differences between North America and Europe. The high prevalence of T2D and widespread advertising of diabetes medication in North America is likely to increase awareness of T2D and its consequences. ${ }^{31}$ Although few respondents expected to experience serious complications in general during the next year, when asked about specific complications many did expect to experience one or more of these in this time frame, particularly microvascular issues, such as neuropathy, retinopathy, sexual dysfunction, and skin problems, rather than cardiovascular issues. There are 
several potential explanations for this response. It may be that patients do not perceive microvascular complications to be "serious," as was found in a telephone-based survey of patients with diabetes in the USA, ${ }^{32}$ or that microvascular outcomes are more apparent in the shorter term. Alternatively, these patients may not associate diabetes with cardiovascular issues, as has been found in previous studies. ${ }^{32,33} \mathrm{~A}$ recent systematic review of studies investigating the perceptions of diabetes-related complication risks in populations with T2D found that patients' perceptions are generally biased, characterized by optimism and low risk awareness. ${ }^{34}$ In line with our findings, the review found that patients were less aware of their risk of experiencing macrovascular vs microvascular complications. Given that half of people with T2D die prematurely from cardiovascular disease, ${ }^{35}$ it appears that patients may not be realistically evaluating their personal risk of developing macrovascular complications.

Patient-reported adherence to diabetes medications in the present study was generally high, albeit somewhat lower for insulin than for oral medications among respondents in the USA and Mexico, where patients may face higher outof-pocket costs of treatment relative to income than in other countries. ${ }^{36,37}$ Surprisingly, while the majority of respondents across countries believed that taking medications for T2D was an important or very important factor in achieving their diabetes goals, over one-quarter of respondents in the UK felt that it was very unimportant. This may suggest that, in comparison with their counterparts in other countries, UK physicians put more emphasis on lifestyle changes than on medication use when communicating with patients. When assessing self-management of their diabetes, respondents across countries appeared to be reasonably confident that they could adequately manage their blood sugar levels. Despite this confidence, a sizeable minority of respondents across countries had clinically significant levels of regimenrelated distress. Diabetes distress has been linked with poor adherence and poor glycemic control, ${ }^{38,39}$ however, greater levels of HCP support can decrease diabetes distress. ${ }^{40,41}$ Improvement in HCP support for patients regarding their treatment, for instance by offering guidance on how often to test blood sugar levels and by providing, or referring patients to, nutrition support, may therefore reduce patient distress and improve diabetes outcomes.

\section{Strengths and limitations}

The major strength of this study is that it assessed data obtained directly from a network of patients with T2D in a real-world setting, offering context that cannot be observed in medical records. Use of an anonymous online survey may improve willingness to disclose sensitive information, such as medication nonadherence. Finally, direct access to patients through online communities enabled a potentially more diverse sample to be reached than could be reached through physicians' offices alone.

Several limitations of this work are noted, the first being sample generalizability and selection bias. The participants were a self-selecting population of patients who were concerned enough with their disease to become members of online health communities, therefore this group may overrepresent patient knowledge of T2D compared with the general T2D population. It may be expected that respondents to online surveys are likely to be younger, more computerliterate, and better educated than the general population. In addition, more participants in this study were female than male. These factors may also impact the generalizability of results to the general population of patients with T2D. A second limitation is that, because the study utilized a convenience sample, the populations from each country were not matched for variables such as age and duration of diabetes, and so were not homogeneously distributed, which may influence the interpretation of study results. A third limitation is that the accuracy of patients' perceptions could not be compared with their clinical data, introducing the possibility of recall bias. A fourth limitation is that participants may have had difficulties understanding the questions posed; some Mexican respondents appeared to conflate $\mathrm{A} 1 \mathrm{C}$ and glucose levels when giving answers to A1C-based questions, providing responses that were clearly out of range for $\mathrm{A} 1 \mathrm{C}$ tests, which led us to exclude these data. The questionnaire was not pretested in each country and we did not send a follow-up survey to assess comprehension.

\section{Conclusion}

Patients' knowledge of their glycemic control and targets, and the potential outcomes of poor control, varied between countries. Awareness of A1C testing and targets was high in the USA but considerably lower in Spain and the UK, and North American respondents anticipated a higher number of complications than European respondents. The majority of respondents across countries felt that their T2D was very or fairly well controlled, and few expected to experience serious complications within 1 year; however, many respondents expected to experience microvascular (rather than macrovascular) complications in this time frame. Our findings highlight the need for clear communication between HCPs and patients to ensure that the latter are aware of their 
A1C levels and targets and to understand what is needed to achieve those targets. The potential consequences of poor glycemic control should also be communicated clearly to patients, including the possibility of macrovascular disease, of which they appear to be less aware. Furthermore, while patient self-reported adherence to medication was generally high and most respondents across countries felt that taking injectable medications was not overly burdensome, a sizeable minority still have regimen-related distress: HCPs should work with patients to support self-management, reduce distress, and improve diabetes outcomes.

\section{Acknowledgments}

We thank all of the study participants for their time in responding to our survey. We also thank Cathy Emmas and Lynn Hagger of AstraZeneca for their contributions to this work. Medical writing support for the manuscript was provided by Richard Claes PhD of Oxford PharmaGenesis, funded by AstraZeneca. This work was supported by AstraZeneca, who provided financial sponsorship for the conduct of the study and preparation of the manuscript.

\section{Author contributions}

Kristina Simacek - conception and design of the study, acquisition and interpretation of data, and drafting and revising of the manuscript. Christopher Curran - conception and design of the study, acquisition and interpretation of data, and revising of the manuscript. Peter Fenici and Ricardo Garcia-Sanchez - conception and design of the study, interpretation of data, and revising of the manuscript. All authors gave final approval of the version to be published, and agree to be accountable for all aspects of the work.

\section{Disclosure}

Kristina Simacek and Christopher Curran are employees of PatientsLikeMe, Inc. and hold stock options in PatientsLikeMe, Inc. They have received research funding (including conference support and consulting fees) from Abbvie, Accorda, Actelion, Alexion, Amgen, AstraZeneca, Avanir, Biogen, Boehringer Ingelheim, Celgene, EMD, Genentech, Genzyme, Janssen, Johnson \& Johnson, Merck, Neuraltus, Novartis, Otsuka, Sanofi, Takeda, and UCB. They have received research grant funding from Kaiser Permanente, the Robert Wood Johnson Foundation, Sage Bionetworks, the AKU Society, and the University of Maryland. Peter Fenici and Ricardo Garcia-Sanchez are current and former employees of AstraZeneca, respectively and may own shares in AstraZeneca.

\section{References}

1. World Health Organization. Global Report on Diabetes. Geneva: World Health Organization; 2016. Available from: http://apps.who.int/iris/ bitstream/10665/204871/1/9789241565257_eng.pdf. Accessed January 17, 2018

2. International Diabetes Federation. Global guideline for type 2. Diabetes. 2012. Available from: https://www.idf.org/e-library/guidelines/79global-guideline-for-type-2-diabetes. Accessed January 17, 2018.

3. American Diabetes Association. Standards of medical care in diabetes - 2017. Diabetes Care. 2017;40(Suppl 1):S1-S132.

4. Garber AJ, Abrahamson MJ, Barzilay JI, et al. AACE/ACE comprehensive diabetes management algorithm 2015. Endocr Pract. 2015; 21(4):438-447.

5. Qaseem A, Humphrey LL, Sweet DE, Starkey M, Shekelle P; Clinical Guidelines Committee of the American College of Physicians. Oral pharmacologic treatment of type 2 diabetes mellitus: a clinical practice guideline from the American College of Physicians. Ann Intern Med. 2012;156(3):218-231.

6. Kilpatrick ES, Das AK, Ørskov C, Berntorp K. Good glycaemic control: an international perspective on bridging the gap between theory and practice in type 2 diabetes. Curr Med Res Opin. 2008;24(9): 2651-2661.

7. Polinski JM, Kim SC, Jiang D, et al. Geographic patterns in patient demographics and insulin use in 18 countries, a global perspective from the multinational observational study assessing insulin use: understanding the challenges associated with progression of therapy (MOSAIc). BMC Endocr Disord. 2015;15(1):46.

8. Stark Casagrande S, Fradkin JE, Saydah SH, Rust KF, Cowie CC. The prevalence of meeting A1c, blood pressure, and LDL goals among people with diabetes, 1988-2010. Diabetes Care. 2013;36(8):2271-2279.

9. Stone MA, Charpentier G, Doggen K, et al. Quality of care of people with type 2 diabetes in eight European countries: findings from the Guideline Adherence to Enhance Care (GUIDANCE) study. Diabetes Care. 2013;36(9):2628-2638.

10. Chan JC, Gagliardino JJ, Baik SH, et al. Multifaceted determinants for achieving glycemic control: the International Diabetes Management Practice Study (IDMPS). Diabetes Care. 2009;32(2):227-233.

11. Harwell TS, Dettori N, Mcdowall JM, et al. Do persons with diabetes know their (A1c) number? Diabetes Educ. 2002;28(1):99-105.

12. Trivedi H, Gray LJ, Seidu S, et al. Self-knowledge of HbAlc in people with type 2 diabetes mellitus and its association with glycaemic control. Prim Care Diabetes. 2017;11(5):414-420.

13. Willaing I, Rogvi SA, Bøgelund M, Almdal T, Schiøtz M. Recall of $\mathrm{HbA} 1 \mathrm{c}$ and self-management behaviours, patient activation, perception of care and diabetes distress in type 2 diabetes. Diabet Med. 2013; 30(4):e139-e142.

14. García-Pérez LE, Álvarez M, Dilla T, Gil-Guillén V, Orozco-Beltrán D. Adherence to therapies in patients with type 2 diabetes. Diabetes Ther. 2013;4(2):175-194.

15. Polonsky WH, Henry RR. Poor medication adherence in type 2 diabetes: recognizing the scope of the problem and its key contributors. Patient Prefer Adherence. 2016;10:1299-1307.

16. Grant R, Adams AS, Trinacty CM, et al. Relationship between patient medication adherence and subsequent clinical inertia in type 2 diabetes Glycemic management. Diabetes Care. 2007;30(4):807-812.

17. Reach G. Patient non-adherence and healthcare-provider inertia are clinical myopia. Diabetes Metab. 2008;34(4):382-385.

18. International Diabetes Federation. IDF Diabetes Atlas, 8th ed; 2017. Available from: http://www.diabetesatlas.org. Accessed January 17, 2018.

19. National Institute for Health and Care Excellence. NICE guideline: type 2 diabetes in adults: management. December 2, 2015. Available from: https://www.nice.org.uk/guidance/ng28. Accessed November 14, 2018. 
20. AWMF. Programm für Nationale VersorgungsLeitlinien. Therapie des Typ-2-Diabetes. Version 4; 2013. Available from: http://www. deutsche-diabetes-gesellschaft.de/fileadmin/Redakteur/Leitlinien/Evidenzbasierte_Leitlinien/dm-therapie-1aufl-vers4-lang.pdf. Accessed November 14, 2018.

21. GuiaSalud. Working group of the Clinical Practice Guideline for type 2 Diabetes. Clinical Practice Guideline on type 2 Diabetes. May 2013. Available from: http://www.guiasalud.es/egpc/traduccion/ingles/ diabetes/completa/index.html. Accessed November 14, 2018.

22. Guía de Práctica Clínica. Diagnóstico y Tratamiento Farmacológico de la Diabetes Mellitus Tipo 2 en el Primer Nivel de Atención. Guía de Evidencias y Recomendaciones. México: Instituto Mexicano del Seguro Social; 2018. Available from: http://www.imss.gob.mx/sites/ all/statics/guiasclinicas/718GER.pdf. Accessed November 14, 2018.

23. Diabetes Canada. 2018 Clinical Practice Guidelines for the Prevention and Management of Diabetes in Canada. Can J Diabetes. 2018; 42(Supp1 1):A1-A18, S11-S326.

24. Lopez JM, Katic BJ, Fitz-Randolph M, Jackson RA, Chow W, Mullins CD. Understanding preferences for type 2 diabetes mellitus selfmanagement support through a patient-centered approach: a 2-phase mixed-methods study. BMC Endocr Disord. 2016;16(1):41.

25. Peyrot M, Rubin RR, Lauritzen T, et al. Resistance to insulin therapy among patients and providers: results of the cross-national Diabetes Attitudes, Wishes, and Needs (DAWN) study. Diabetes Care. 2005; 28(11):2673-2679.

26. Skeie $S$, Thue $G$, Sandberg S. Interpretation of hemoglobin A(1c) $(\mathrm{HbA}(1 \mathrm{c}))$ values among diabetic patients: implications for quality specifications for HbA(1c). Clin Chem. 2001;47(7):1212-1217.

27. Polonsky WH, Fisher L, Earles J, et al. Assessing psychosocial distress in diabetes: development of the Diabetes Distress Scale. Diabetes Care. 2005;28(3):626-631.

28. Coulter A, Jenkinson C. European patients' views on the responsiveness of health systems and healthcare providers. Eur J Public Health. 2005; 15(4):355-360

29. Comité Consultivo Nacional de Normalización de Regulación y Fomento Sanitario. Norma Oficial Mexicana del Expediente Clínico, NOM-168-SSA1-1998 (Section 5.5). Rev Mex Patol Clin. 2000;47(4):245-253. Available from: http://www.medigraphic.com/ pdfs/patol/pt-2000/pt004g.pdf. Accessed April 3, 2018.
30. Centers for Medicare and Medicaid Services, H. H. S.; Centers for Disease, Control and Prevention, H. H. S.; Office for Civil Rights, H. H. S. CLIA program and HIPAA privacy rule; patients' access to test reports. Final rule. Fed Regist. 2014;79(25):7289-7316.

31. Singh BM, Prescott JJ, Guy R, Walford S, Murphy M, Wise PH. Effect of advertising on awareness of symptoms of diabetes among the general public: the British Diabetic Association Study. BMJ. 1994;308(6929): 632-636.

32. Merz CN, Buse JB, Tuncer D, Twillman GB. Physician attitudes and practices and patient awareness of the cardiovascular complications of diabetes. J Am Coll Cardiol. 2002;40(10):1877-1881.

33. O'Sullivan EP, Bhargava A, O'Callaghan M, et al. Awareness of diabetes complications in an Irish population. Ir J Med Sci. 2009;178(4): 401-406.

34. Rouyard T, Kent S, Baskerville R, Leal J, Gray A. Perceptions of risks for diabetes-related complications in type 2 diabetes populations: a systematic review. Diabet Med. 2017;34(4):467-477.

35. van Dieren S, Beulens JW, van der Schouw YT, Grobbee DE, Neal B. The global burden of diabetes and its complications: an emerging pandemic. Eur J Cardiovasc Prev Rehabil. 2010;17(Suppl 1):S3-S8.

36. Arredondo A, Barceló A. The economic burden of out-of-pocket medical expenditures for patients seeking diabetes care in Mexico. Diabetologia. 2007;50(11):2408-2409.

37. Seuring T, Archangelidi O, Suhrcke M. The economic costs of type 2 diabetes: a global systematic review. Pharmacoeconomics. 2015;33(8):811-831.

38. Pandit AU, Bailey SC, Curtis LM, et al. Disease-related distress, selfcare and clinical outcomes among low-income patients with diabetes. J Epidemiol Community Health. 2014;68(6):557-564.

39. van Bastelaar KMP, Pouwer F, Geelhoed-Duijvestijn PHLM, et al. Diabetes-specific emotional distress mediates the association between depressive symptoms and glycaemic control in Type 1 and Type 2 diabetes. Diabet Med. 2010;27(7):798-803.

40. Wardian J, Sun F. Factors associated with diabetes-related distress: implications for diabetes self-management. Soc Work Health Care. 2014; 53(4):364-381.

41. Delahanty LM, Grant RW, Wittenberg E, et al. Association of diabetesrelated emotional distress with diabetes treatment in primary care patients with type 2 diabetes. Diabet Med. 2007;24(1):48-54.
Patient Preference and Adherence

\section{Publish your work in this journal}

Patient Preference and Adherence is an international, peer-reviewed, open access journal that focuses on the growing importance of patient preference and adherence throughout the therapeutic continuum. Patient satisfaction, acceptability, quality of life, compliance, persistence and their role in developing new therapeutic modalities and compounds to optimize

\section{Dovepress}

clinical outcomes for existing disease states are major areas of interest for the journal. This journal has been accepted for indexing on PubMed Central. The manuscript management system is completely online and includes a very quick and fair peer-review system, which is all easy to use. Visit http://www. dovepress.com/testimonials.php to read real quotes from published authors. 